\title{
Get your own mirror : investigating how strict eating disordered women are in judging the bodies of other eating disordered women
}

Citation for published version (APA):

Alleva, J., Jansen, A., Martijn, C., Schepers, J., \& Nederkoorn, C. (2013). Get your own mirror : investigating how strict eating disordered women are in judging the bodies of other eating disordered women. Appetite, 68, 98-104. https://doi.org/10.1016/j.appet.2013.04.015

Document status and date:

Published: 01/09/2013

DOI:

10.1016/j.appet.2013.04.015

Document Version:

Publisher's PDF, also known as Version of record

Document license:

Taverne

Please check the document version of this publication:

- A submitted manuscript is the version of the article upon submission and before peer-review. There can be important differences between the submitted version and the official published version of record.

People interested in the research are advised to contact the author for the final version of the publication, or visit the DOI to the publisher's website.

- The final author version and the galley proof are versions of the publication after peer review.

- The final published version features the final layout of the paper including the volume, issue and page numbers.

Link to publication

\footnotetext{
General rights rights.

- You may freely distribute the URL identifying the publication in the public portal. please follow below link for the End User Agreement:

www.umlib.nl/taverne-license

Take down policy

If you believe that this document breaches copyright please contact us at:

repository@maastrichtuniversity.nl

providing details and we will investigate your claim.
}

Copyright and moral rights for the publications made accessible in the public portal are retained by the authors and/or other copyright owners and it is a condition of accessing publications that users recognise and abide by the legal requirements associated with these

- Users may download and print one copy of any publication from the public portal for the purpose of private study or research.

- You may not further distribute the material or use it for any profit-making activity or commercial gain

If the publication is distributed under the terms of Article $25 \mathrm{fa}$ of the Dutch Copyright Act, indicated by the "Taverne" license above, 
Research report

\title{
Get your own mirror. Investigating how strict eating disordered women are in judging the bodies of other eating disordered women ${ }^{2 / 2}$
}

\author{
Jessica Alleva*, Anita Jansen, Carolien Martijn, Jan Schepers, Chantal Nederkoorn \\ Maastricht University, Department of Clinical Psychological Science, P.O. Box 616, 6200 MD Maastricht, The Netherlands
}

\section{A R T I C L E I N F O}

\section{Article history:}

Received 17 September 2012

Received in revised form 24 March 2013

Accepted 17 April 2013

Available online 24 April 2013

\section{Keywords:}

Body image

Eating disorders

Mirror exposure

\begin{abstract}
A B S T R A C T
Previous research has shown that eating disordered women lack a self-serving body image bias and largely make self-defeating social comparisons. These factors influence how eating disordered women feel about their bodies, and may also influence treatment for disordered eating. In group mirror exposure therapy, women inevitably compare their own bodies to other women's bodies. Yet, how eating disordered women view their own bodies in relation to other women's bodies has never been investigated. This study investigated how subjects high in eating disorder symptoms ("high symptomatics") view the bodies of other women and of other high symptomatics specifically. Twelve high symptomatics and 13 low symptomatics viewed photos of, and rated the attractiveness of, their own and other participants' bodies. The results show that low symptomatics rated both other women's bodies and other low symptomatic bodies specifically as less attractive, but not as fatter, than their own bodies. In contrast, high symptomatics rated both other women's bodies and other high symptomatic bodies specifically as equally (un)attractive, but as thinner than their own bodies. These results suggest that high symptomatics lack a self-serving body image bias when it comes to aspects of weight specifically. Considering weight is a self-relevant dimension to eating disordered women, the impact of these self-defeating comparisons may be especially negative and may impede treatment progress.
\end{abstract}

(c) 2013 Elsevier Ltd. All rights reserved.

\section{Introduction}

For women with an eating disorder, looking into the mirror can be damaging, as these women are likely to scrutinise their body and focus on their disliked body parts (e.g., Fairburn, 2008; Jansen, Nederkoorn, \& Mulkens, 2005). Yet a mirror can also be a useful tool for the treatment of eating disorder patients. During 'mirror (or body) exposure,' the individual stands in front of a mirror, for an extended period of time, possibly over several sessions. Different variants of mirror exposure exist, including: asking the individual to describe his or her body in a neutral way (e.g., Delinsky \& Wilson, 2006; Hilbert, Tuschen-Caffier, \& Vögele, 2002; Jansen, Bollen, Tuschen-Caffier, Roefs, Tanghe, \& Braet, 2008; Moreno-Dominguez, Rodriguez-Ruiz, Fernandez-Santaella, Jansen, \& TuschenCaffier, 2012) which may de-emphasise negative evaluations; asking the individual to describe his or her body in a positive way (e.g., Luethcke, McDaniel, \& Becker, 2011; Stice \& Presnell, 2007) which may instill new, positive evaluations; or exposing the individual

\footnotetext{
Acknowledgement: The contribution of Alleva was supported by NWO grant 40410-118: Novel strategies to enhance body satisfaction.

* Corresponding author.

E-mail addresses: jessica.alleva@maastrichtuniversity.nl (J. Alleva), a.jansen@maastrichtuniversity.nl (A. Jansen), c.martijn@maastrichtuniversity.nl (C. Martijn), c.nederkoorn@maastrichtuniversity.nl (C. Nederkoorn).
}

without guidance at all ('pure exposure') which may work via the traditional extinction route (e.g., Moreno-Dominguez et al., 2012).

To date, it appears that mirror exposure can be beneficial in treating eating disorder patients. However, it is important to recognise that there may be risks associated with mirror exposure. This risk is due in part to the peculiar way that eating disorder patients see their own and others' bodies. In a study of Jansen, Smeets, Martijn, and Nederkoorn (2006) a panel of independent judges rated the attractiveness of eating disordered and control participants. Despite the fact that control participants and eating disordered participants did not differ in body mass index (BMI), the eating disordered participants received lower attractiveness ratings from the panel. Moreover, these ratings also matched their own ratings. On the contrary, control participants received somewhat higher ratings from the panel, but these ratings were lower than the control participants' own ratings. Further, a second panel rated the most attractive and most unattractive body parts of the participants (Jansen et al., 2006). The results showed that there was larger agreement between the panel-identified and self-identified most unattractive body parts in the eating disordered participants compared to the agreement between the panel and the control participants. The researchers concluded that eating disordered individuals are more realistic and lack a "self-serving body image bias" that may buffer against body dissatisfaction and disordered eating. Similar to depressed pa- 
tients (e.g., Brewin, 1993) they may also be "sadder but wiser," specifically in terms of their body image. In essence, the control subjects were the ones with the perceptual distortion, albeit a healthy, protective one.

Eating disordered individuals may also see others women's bodies differently than healthy women do. Jansen et al. (2005) exposed eating disordered and control participants to pictures of their own bodies and to pictures of other women's bodies. Visual attention was measured using eye movement registration. The results showed that eating disordered participants attended more to their self-identified unattractive body parts whereas control participants attended more to their self-identified attractive body parts. In contrast, when looking at other bodies, eating disordered participants attended more to the attractive body parts whereas control participants attended more to the unattractive body parts of other bodies. These findings also indicate the presence of the self-serving body image bias in control participants, and the lack thereof in eating disordered participants. Furthermore, inducing a negative bias (focusing on the self-defined unattractive body parts) in healthy women leads to a decrease in body satisfaction (Smeets, Jansen, \& Roefs, 2011). Thus, the tendency of eating disordered participants to focus on their unattractive body parts may be causal to body dissatisfaction (Smeets et al., 2011).

Finally, it is important to note that, in clinical practice, mirror exposure is often conducted in group format. In these sessions, one patient stands in front of the mirror and describes his or her body and the other patients are invited to respond to his or her descriptions. Although mirror exposure, and group therapy in general, is aimed at improving individual well-being, group mirror exposure inevitably introduces social influences. The social comparison theory may shed light on how these social factors may affect eating disordered individuals' experience of therapy. The social comparison theory posits that individuals compare themselves to others in order to gauge their standing in a particular aspect of the self (Festinger, 1954). Individuals may make social comparisons on various dimensions (e.g., appearance) and with various 'targets' (e.g., one's friends). Moreover, comparisons may be in the upward direction (i.e., with a target who perceivably fares better on the particular dimension) or in the downward direction (i.e., with a target who perceivably fares worse on the particular dimension). Upward comparisons (e.g., "I'm less beautiful than her") may lead to feelings of distress or lower self-worth, whereas downward comparisons (e.g., "I'm more beautiful than her") may lead to feelings of increased self-worth and satisfaction (Festinger, 1954). Also, social comparisons made on self-relevant dimensions and with similar others have a greater impact on one's self-worth than those made on irrelevant dimensions and with dissimilar others (Wood, 1989).

To date, research has shown that social comparisons play an important role in eating disorders and in body dissatisfaction (one of the main risk factors for developing an eating disorder; Stice, 2002). For instance, Morrison, Kalin, and Morrison (2004) have demonstrated that universalistic social comparisons predicted appearance self-esteem, body dissatisfaction, number of diets to lose weight and engagement in weight control practices. Also, Corning, Krumm, and Smitham (2006) have shown that women high in eating disorder symptoms make social comparisons more often than asymptomatic women do. Moreover, the tendency to make self-defeating social comparisons was shown to predict eating disorder symptoms in this sample. Regarding body dissatisfaction, a meta-analysis by Myers and Crowther (2009) has shown that social comparison making is related to higher levels of body dissatisfaction.

As aforementioned, social comparison theory may elucidate social processes that affect eating disordered individuals during mirror exposure. Group mirror exposure creates a social setting where social comparisons are unavoidable. Eating disordered women tend to make self-defeating social comparisons with other women (Corning et al., 2006), which they will likely do in the mirror exposure setting. Relatedly, the aforesaid experimental findings suggest that eating disordered individuals focus on the beautiful body parts of other people (Jansen et al., 2005) and lack a self-serving body image bias-both factors which will also affect social comparisons made in group therapy. In sum, as a result of these influences, eating disordered women may feel fatter or less attractive than their fellow peers, which may induce increased distress and ultimately impede the therapeutic process. Importantly, the social comparisons made in mirror exposure are likely to be especially impactful, as they target a dimension that is highly relevant to eating disordered individuals (weight) and are made with individuals who are similar to them (other eating disordered individuals).

Surprisingly, despite the potential impact of the way eating disordered individuals see and make comparisons with other women, how eating disordered individuals judge the bodies of other women (and of other eating disordered women specifically) has never been tested. Therefore, the aim of the current experiment is to investigate whether or not eating disordered participants evaluate the bodies of other participants more positively than their own bodies and whether their strict judgment is limited to their own body. To do this, female participants high in eating disorder symptoms ("high symptomatics") rated the attractiveness of other eating disordered and control bodies. Their ratings were compared with ratings made by female participants that were low in eating disorder symptoms ("low symptomatics"). It was expected that high symptomatics would see all other bodies as more attractive than their own (hypothesis 1a), reflecting the ultimate lack of a self-serving body image bias and the tendency to make self-defeating comparisons with other women. In contrast, it was expected that low symptomatics would see all other bodies as less attractive than their own (hypothesis $1 \mathrm{~b}$ ), reflecting both their tendency to attend to the unattractive aspects of other bodies and the presence of a self-serving body image bias. It was further expected that high symptomatics would also judge the bodies of other high symptomatics as more attractive than their own (again, reflecting the ultimate lack of a self-serving bias and the tendency to selectively focus on the attractive aspects of other bodies; hypothesis 2a). It is vital to investigate this comparison specifically as it is directly relevant to group mirror exposure and clinical settings in general. Contrarily, it was hypothesised that low symptomatics would rate their own bodies as significantly more attractive than the bodies of other low symptomatics (hypothesis $2 \mathrm{~b}$ ).

Finally, in order to assess how participants think other people judge their bodies, compared to their self-assessments, participants were also asked to estimate how an 'average Dutch male' would rate their attractiveness, as well as the attractiveness of the other bodies. In line with the hypotheses above, it was expected that high symptomatics would expect men to rate other bodies as more attractive than their bodies (demonstrating the lack of a self-serving bias; hypothesis 3a), whereas low symptomatics would expect men to rate other bodies as less attractive than their bodies (demonstrating the ultimate self-serving bias; hypothesis $3 \mathrm{~b}$ ).

\section{Methods}

\section{Participants}

Participants were invited to take part in a study that was said to be about the relation between character and perception. It was made clear that participants should be willing to be photographed in underclothing. Volunteers were selected based on the highest 
(high symptomatics, $n=13$ ) and lowest levels (low symptomatics, $n=13$ ) of eating disorder symptomatology, as measured by the EDE-Q (see Assessment). One participant dropped out due to pregnancy. There were thus 25 participants in total, 12 high symptomatics and 13 low symptomatics. The current participants first participated in a study on selective visual attention and body (dis)satisfaction that was published previously (Jansen et al., 2005). After they completed the eye tracking task, during which their eye movements were registered, they had a 10 min break. The participants then came to another laboratory room to participate in the present task.

\section{Body photographs}

The body photographs were taken by a professional photographer in the university photo studio. The participants stood in front of a blue screen, dressed in standard underclothing (beige colored bra and underwear). They stood facing the camera, arms hanging loosely beside the body. One photograph was taken of each participant (in frontal view), without the head in the frame.

\section{Assessment}

The Eating Disorder Examination-Questionnaire (EDE-Q; Fairburn \& Beglin, 1994) was used to quantify eating disorder psychopathology. The EDE-Q is a widely-used self-report instrument that measures the presence and severity of disordered eating behavior and cognitions. The EDE-Q consists of 38 items, concerning the previous 28 days, and contains four subscales: restraint (five items), eating concern (five items), shape concern (eight items) and weight concern (five items).). Answers are gathered on 7-point Likert scales ranging from $0=$ not at all, to $6=$ highly frequent (higher scores represent more eating pathology). The restraint subscale measures the intention to restrict or avoid food intake (e.g., "Have you gone for long periods of time ( $8 \mathrm{~h}$ or more) without eating anything in order to influence your weight?"). The eating concern subscale measures obsessive thoughts about calories or eating (e.g., "Has thinking about food or its calorie content made it much more difficult to concentrate on things you are interested in; for example, read, watch TV, or follow a conversation?"). The shape and weight concern subscales measure preoccupation with shape and weight as well as the value of weight in overall self-evaluation (e.g., "Has your shape/weight influenced how you think about (judge) yourself as a person?"). The EDE-Q is a valid, effective and psychometrically sound measure (Luce \& Cwother, 1999; Wilfey, Schwartz, Spurrell, \& Fairburn, 1997).

In order to judge the attractiveness of their own body and other bodies, participants gave a grade between 0 (very negative) to 10 (very positive) for each body photograph. They also rated the bodies using three $100 \mathrm{~mm}$ visual analogue scales (VAS) for unattractiveness-attractiveness, ugliness-beauty, and fatness-thinness. Participants also gave the bodies a grade $(0=$ very negative to $10=$ very positive) based on how they think the 'average Dutch male' would rate the bodies. They also rated the bodies based on the same three $100 \mathrm{~mm}$ VAS scales, this time from the perspective of the 'average Dutch male.'

The body mass index (BMI) was determined with the formula: weight in kilograms divided by the square of height in metres. The waist to hip ratio (WHR) was determined with the formula: circumference of the waist divided by the circumference of the hips, in centimetres.

\section{Procedure}

Each participant signed an informed consent and was tested individually. She was seated in front of a wall and told that she would see a series of body photographs projected there. She was instructed to rate the general attractiveness of the presented body with a grade between 0 (very negative) and 10 (very positive) and to fill in the three VAS scales. She should also give a grade between 0 and 10 according to how she thinks the 'average Dutch male' would rate the presented body, and fill in the remaining three VAS scales (from the perspective of the 'average Dutch male'). She was informed that her own body would appear first, followed by images of other bodies. It is important to note that she did not know whether the other bodies were high or low symptomatic bodies. Starting with the participant's own body, 25 bodies were presented for $60 \mathrm{~s}$ each. For each participant the bodies were presented in a new randomized order (with the participant's own body always appearing first). Between each body there was a $5 \mathrm{~s}$ pause. After the 25 bodies were evaluated, the participant was instructed to evaluate various paintings (as part of a separate study with separate hypotheses). She then filled in the EDE-Q. Finally, her weight, height, waist and hip circumference were measured by the experimenter. The participant was then thanked, given a monetary compensation and fully debriefed.

\section{Statistical analysis}

To test hypotheses $1 \mathrm{a}$ and $1 \mathrm{~b}$, the data were analyzed in a 2 between (Group: high symptomatics vs. low symptomatics) $\times 2$ within (Body Photograph: own body vs. other body) repeated measures MANOVA. To test hypotheses $2 \mathrm{a}$ and $2 \mathrm{~b}$, the data were analyzed in a 2 between (Group: high symptomatic vs. low symptomatic) $\times 3$ within (Body Photograph: own body, high symptomatic body, low symptomatic body) repeated measures MANOVA.

Dependent variables were the ratings for each body on the 0-10 grade scale and on the three VAS measures. Finally, to test hypotheses $3 a$ and $3 b$, ratings from the perspective of the average Dutch male' were analyzed in a 2 between (Group: high symptomatic vs. low symptomatic) $\times 2$ within (Body Photograph: own body vs. other body) repeated measures MANOVA. In cases where the assumption of sphericity was not met, a Greenhouse-Geisser correction was applied.

\section{Results}

\section{Participant characteristics}

There were no group differences in age, body mass index (BMI) or waist-to-hip ratio (WHR) at test day between the high and low symptomatic participants, ts varied between 0.44 and 2.45 , ns (see Table 1). To check for group differences in eating disorder pathology, a MANOVA was conducted with Group as independent variable and the subscale and total scores of the EDE-Q as dependent variables. The effect of Group was significant, $F(4,20)=16.89$, $p<0.001, \eta_{p}^{2}=0.77$, such that the high symptomatic group scored higher on all subscales and on the total score of the EDE-Q, Fs varied between 16.67 and 66.22, $p<0.001$. The EDE-Q scores of the high symptomatic group were about as high as the EDE scores of an Eating Disorders Not Otherwise Specified sample (Hay \& Fairburn, 1998).

\section{Hypothesis $1 a$ and $1 b$}

Results of a repeated measures MANOVA showed a significant interaction between Group and Body Photograph on the three VAS scales, $F(3,21)=8.79, p=0.001, \eta_{p}^{2}=0.56$.

Hypothesis 1a was that high symptomatics would rate all other bodies as significantly more attractive than their own bodies. The 
Table 1

Descriptive statistics.

\begin{tabular}{|c|c|c|c|c|}
\hline & \multicolumn{2}{|c|}{$\underline{\text { High symptomatics }}$} & \multicolumn{2}{|c|}{ Low symptomatics } \\
\hline & $M$ & $S D$ & $M$ & $S D$ \\
\hline Age & 22.42 & 3.90 & 21.08 & 2.18 \\
\hline $\mathrm{BMI}^{\mathrm{a}}$ & 22.00 & 2.82 & 21.53 & 2.58 \\
\hline WHR ${ }^{\mathrm{b}}$ & 0.73 & 0.03 & 0.71 & 0.06 \\
\hline \multicolumn{5}{|l|}{$E D E-Q^{c}$} \\
\hline Global Score & 2.90 & 1.12 & 0.55 & 0.36 \\
\hline Restraint & 2.33 & 1.37 & 0.48 & 0.50 \\
\hline Eating concern & 2.13 & 1.69 & 0.22 & 0.17 \\
\hline Shape concern & 3.83 & 1.29 & 0.89 & 0.52 \\
\hline Weight concern & 3.30 & 1.04 & 0.60 & 0.58 \\
\hline
\end{tabular}

a $\mathrm{BMI}=$ body-mass index.

b WHR = waist to hip ratio

c $\mathrm{EDE}-\mathrm{Q}=$ Eating Disorder Examination-Questionnaire.

univariate tests showed significant interactions between Group and Body Photograph on VAS1 (unattractive-attractive), $F(1,23)=25.30, p<0.001, \eta_{p}^{2}=0.52$, on VAS2 (ugly-beautiful), $F(1,23)=21.40, p<0.001, \eta_{p}^{2}=0.48$, and on VAS3 (fat-thin), $F(1,23)=8.34, p<0.01, \eta_{p}^{2}=0.27$, suggesting that high and low symptomatics rated the body photographs differently on each scale (see Tables 2 and 3). A follow-up repeated measures MANOVA, separated by Group, clarified these results: high symptomatics did not rate other bodies differently on VAS1 (unattractive-attractive), $F(1,11)=3.60, p>0.05$, $n s$, or on VAS2 (ugly-beautiful), $F(1,11)=1.09, p>0.05$, ns. However, high symptomatics did rate other bodies as thinner than their own bodies, VAS3 (fat-thin), $F(1,11)=9.09, p<0.05, \eta_{p}^{2}=0.45$.

Results of a repeated measures ANOVA showed a significant interaction between Group and Body Photograph on the attractiveness grade, $F(1,23)=8.55, p<0.01, \eta_{p}^{2}=0.27$. Follow-up $t$-tests showed that the attractiveness grade high symptomatics gave to other bodies did not differ from the attractiveness grades they gave their own bodies, $t(11)=1.29, n s$. Therefore, high symptomatics rated other bodies just as unattractive as they rated their own.

Hypothesis $1 \mathrm{~b}$ was that low symptomatics would rate all other bodies as significantly less attractive than their own bodies. In line with this hypothesis, low symptomatics rated their own bodies as more attractive than the other bodies concerning VAS1 (unattrac- tive-attractive), $F(1,12)=25.74, p<0.001, \eta_{p}^{2}=0.68$, and VAS2 (ugly-beautiful), $F(1,12)=44.79, p<0.001, \eta_{p}^{2}=0.79$. However, they did not rate other bodies differently concerning VAS3 (fatthin), $F(1,12)=1.84, p>0.05$, $n s$.

Regarding the attractiveness grade, the follow-up $t$-tests of the repeated measures ANOVA showed that low symptomatics rated their own bodies as more attractive than the other bodies, $t(12)=4.79, p<0.001, d=2.77$.

\section{Hypothesis $2 a$ and $2 b$}

Results of a repeated measures MANOVA showed a significant interaction between Group and Body Photograph on the three VAS scales, $F(6,90)=3.72, p<0.01, \eta_{p}^{2}=0.20$.

Hypothesis 2a was that high symptomatics would rate other high symptomatic bodies as significantly more attractive than their own bodies. The univariate tests showed significant interactions between Group and Body Photograph on VAS1 (unattractiveattractive), $\quad F(1.23,28.33)=9.70, p<0.01, \quad \eta_{p}^{2}=0.30$, on VAS2 (ugly-beautiful), $F(1.20,27.60)=6.84, p=0.01, \eta_{p}^{2}=0.22$, and on VAS3 (fat-thin), $F(1.11,25.62)=9.91, p<0.01, \eta_{p}^{2}=0.30$, suggesting that high and low symptomatics rated the body photographs differently on each scale. A follow-up repeated measures MANOVA, separated by Group, clarified these results: high symptomatics did not rate other high symptomatic bodies differently on VAS1 (unattractive-attractive), $F(1.11,12.26)=2.94, p>0.05, \eta_{p}^{2}=0.21$, or on VAS2 (ugly-beautiful), $F(1.15,12.65)=2.65, p>0.05, \quad \eta_{p}^{2}=0.19$. However, high symptomatics rated other high symptomatic bodies as thinner than their own bodies, VAS3 (fat-thin), $F(1.13,12.48)=10.31, p=0.01, \eta_{p}^{2}=0.48$.

Results of a repeated measures ANOVA showed a significant interaction between Group and Body Photograph on the attractiveness grade, $F(2,22)=6.20, p<0.05, \eta_{p}^{2}=0.27$. Follow-up $t$-tests showed that the attractiveness grade high symptomatics gave to other high symptomatic bodies did not differ from the attractiveness grades they gave their own bodies, $t(11)=0.75, n s$. Therefore, high symptomatics rated other high symptomatic bodies just as unattractive as they rated their own.

Hypothesis $2 \mathrm{~b}$ was that low symptomatics would rate their own bodies as significantly more attractive than the bodies of other low

Table 2

Attractiveness ratings given by high symptomatic participants to their own and others' bodies.

\begin{tabular}{|c|c|c|c|c|c|c|c|c|}
\hline & \multicolumn{2}{|c|}{ Own body } & \multicolumn{2}{|c|}{ Other body } & \multicolumn{2}{|c|}{$\mathrm{HS}^{\mathrm{a}}$ body } & \multicolumn{2}{|c|}{$\mathrm{LS}^{\mathrm{b}}$ body } \\
\hline & $M$ & $S D$ & $M$ & $S D$ & $M$ & $S D$ & $M$ & $S D$ \\
\hline Unattractive-attractive & 42.08 & 15.54 & 50.40 & 8.19 & 45.58 & 8.61 & 53.42 & 8.67 \\
\hline Ugly-beautiful & 42.58 & 21.33 & 49.38 & 7.07 & 46.50 & 9.11 & 54.92 & 6.83 \\
\hline Fat-thin & 34.33 & 15.62 & 51.16 & 8.89 & 45.00 & 7.03 & 52.75 & 11.28 \\
\hline Grade & 5.71 & 1.74 & 6.37 & 0.48 & 6.11 & 0.51 & 6.61 & 0.48 \\
\hline
\end{tabular}

Note: For all scales, a higher score represents a more positive rating.

${ }^{\text {a }} \mathrm{HS}=$ high symptomatics.

b $\mathrm{LS}=$ low symptomatics.

Table 3

Attractiveness ratings given by low symptomatic participants to their own and others' bodies.

\begin{tabular}{|c|c|c|c|c|c|c|c|c|}
\hline & \multicolumn{2}{|c|}{ Own body } & \multicolumn{2}{|c|}{ Other body } & \multicolumn{2}{|c|}{$\mathrm{HS}^{\mathrm{a}}$ body } & \multicolumn{2}{|c|}{$\mathrm{LS}^{\mathrm{b}}$ body } \\
\hline & $M$ & $S D$ & $M$ & $S D$ & $M$ & $S D$ & $M$ & $S D$ \\
\hline Unattractive-attractive & 69.31 & 10.79 & 43.94 & 10.19 & 51.69 & 11.76 & 60.38 & 9.70 \\
\hline Ugly-beautiful & 70.00 & 10.58 & 41.14 & 8.94 & 56.31 & 10.31 & 61.46 & 8.53 \\
\hline Fat-thin & 57.77 & 18.83 & 48.02 & 9.52 & 48.54 & 9.25 & 55.31 & 9.88 \\
\hline Grade & 7.50 & 0.50 & 6.62 & 0.66 & 6.27 & 0.80 & 6.95 & 0.63 \\
\hline
\end{tabular}

Note: For all scales, a higher score represents a more positive rating.

a $\mathrm{HS}=$ high symptomatics.

b $\mathrm{LS}=$ low symptomatics. 
symptomatics. In line with the hypothesis, low symptomatics rated their own bodies as more attractive than the bodies of other low symptomatics concerning VAS1 (unattractive-attractive), $F(2,24)=20.20, p<0.001, \eta_{p}^{2}=0.63$ and VAS2 (ugly-beautiful), $F(1.35,16.23)=11.21, p<0.01, \eta_{p}^{2}=0.48$. However, they did not rate other low symptomatic bodies differently concerning VAS3 (fat-thin), $F(1.07,12.82)=3.89, p>0.05, \eta_{p}^{2}=0.25$.

Regarding the attractiveness grade, the follow-up $t$-tests of the repeated measures ANOVA showed that low symptomatics rated their own bodies as more attractive than the bodies of other low symptomatics, $t(12)=3.07, p<0.01, d=1.77$.

\section{Hypothesis $3 a$ and $3 b$}

The ratings that high and low symptomatic participants gave their own and other bodies, from a male perspective, is given in Table 4. Results for the repeated measures MANOVA showed a significant interaction between Group and Body Photograph, $F(3,21)=4.04, p<0.05, \eta_{p}^{2}=0.37$.

Hypothesis 3a was that high symptomatics would expect men to rate other bodies as more attractive than their own bodies. The univariate tests showed significant interactions between Group and Body Photograph on VAS4 (unattractive-attractive), $F(1,23)=11.49, \quad p<0.01, \quad \eta_{p}^{2}=0.33$, on VAS5 (ugly-beautiful), $F(1,23)=11.18, \quad p<0.01, \quad \eta_{p}^{2}=0.33$ and on VAS6 (fat-thin), $F(1,23)=7.12, p=0.01, \eta_{p}^{2}=0.24$, suggesting that high and low symptomatics expected males to rate the body photographs differently on each scale. To clarify these results, a follow-up repeated measures MANOVA, separated by group, was performed: high symptomatics expected males to rate other bodies more positively on VAS1 (unattractive-attractive), $F(1,11)=8.30, p<0.05, \eta_{p}^{2}=$ 0.43 , on VAS2 (ugly-beautiful), $F(1,11)=6.96, p<0.05, \eta_{p}^{2}=0.39$, and on VAS3 (fat-thin), $F(1,11)=7.69, p<0.05, \eta_{p}^{2}=0.41$.

Results from a second repeated measures ANOVA showed a significant interaction between Group and Body Photograph, $F(1,23)=7.88, p=0.01, \eta_{p}^{2}=0.26$, on the attractiveness grademale perspective. Results from the follow-up $t$-tests were also in line with the hypothesis and showed that high symptomatics think that the average Dutch male would rate other bodies as more attractive than their bodies, $t(11)=2.37, p<0.05, d=1.43$.

Hypothesis $3 \mathrm{~b}$ was that low symptomatics would expect men to rate other bodies as less attractive than their own bodies. Contrary to this hypothesis, low symptomatics did not expect men to rate other bodies as less attractive than their bodies concerning VAS4 (unattractive-attractive), $F(1,12)=2.93, p>0.05, \eta_{p}^{2}=0.20$, VAS5 (ugly-beautiful), $F(1,12)=3.94, p>0.05, \eta_{p}^{2}=0.25$, and VAS6 (fat-thin), $F(1,12)=1.09, p>0.05, \eta_{p}^{2}=0.08$. Similarly, concerning the attractiveness grade, results of the follow-up $t$-tests from the repeated measures ANOVA showed that low symptomatics think that the average Dutch male would rate other bodies no differently than they would rate their own bodies, $t(12)=1.47, p>0.05$, $d=0.85$.

\section{Discussion}

The aim of the current experiment is to investigate whether or not high symptomatics evaluate other bodies more positively than their own bodies and whether their strict judgment is limited to their own body. It is important to understand the ways in which high symptomatic individuals evaluate their own and other bodies, as previous studies have shown that the way they view their own bodies in relation to other women's bodies may be related to disordered eating and body dissatisfaction. Moreover, in clinical practice mirror exposure is often conducted in group format, where individuals comment on their own and on others' bodies. Group mirror exposure creates a social setting where the judgments women make of their own bodies in relation to the other women's bodies may be especially impactful. In the current study, all participants rated the attractiveness of their own bodies, as well as the attractiveness of other (high and low symptomatic) bodies. They did not know whether the other bodies were of high or low symptomatic women, they merely rated a series of other bodies. Participants also rated the bodies according to how they thought the 'average Dutch male' would rate them.

The results of the analyses showed that high symptomatics do not rate other bodies differently than their own bodies except when it comes to the concept of 'fat-thin.' High symptomatics rate other bodies as thinner than their own bodies. Similarly, high symptomatics do not rate other high symptomatic bodies differently than their own bodies, but they did rate other high symptomatic bodies as thinner than their own bodies (note that the average BMI of the high symptomatics was in the normal range and standard deviations were small). Furthermore, high symptomatics expect the 'average Dutch male' to rate other bodies more positively than their own body on all aspects of appearance that were measured. As for low symptomatics, they rated other bodies as less attractive and less beautiful than their own bodies. However, low symptomatics rated other bodies no differently when it came to matters of 'fat-thin.' They also rated other low symptomatic bodies as less attractive and less beautiful than their own bodies, but as equally thin. Finally, low symptomatics did not expect the 'average Dutch male' to rate other bodies more positively than their own bodies.

The main unique finding of the current study is that high symptomatics rate other women's bodies as thinner than their own bodies. This finding was also specific for other high symptomatics, whom they judged to be thinner, as well. For high symptomatic women, thinness may be a particularly self-relevant and salient dimension. Drawing from social comparison theory, comparisons made on self-relevant dimensions are especially impactful (Wood, 1989). Thus, although the high symptomatics judged other bodies as equally (un)attractive, it may be the social comparisons made on the dimension of fat-thin that matter the most to them. Moreover, social comparison theory also posits that comparisons made with similar others have a greater influence on self-worth (Wood,

Table 4

Attractiveness ratings given by high and low symptomatics participants to their own and others' bodies from a male perspective.

\begin{tabular}{|c|c|c|c|c|c|c|c|c|}
\hline & \multicolumn{4}{|c|}{$\mathrm{HS}^{\mathrm{a}}$ participants - male perspective } & \multicolumn{4}{|c|}{$\mathrm{LS}^{\mathrm{b}}$ participants - male perspective } \\
\hline & \multicolumn{2}{|c|}{ Own body } & \multicolumn{2}{|c|}{ Other body } & \multicolumn{2}{|c|}{ Own body } & \multicolumn{2}{|c|}{ Other body } \\
\hline & $M$ & $S D$ & $M$ & $S D$ & $M$ & $S D$ & $M$ & $S D$ \\
\hline Unattractive-attractive & 40.92 & 18.11 & 56.63 & 8.19 & 67.62 & 12.82 & 61.19 & 9.17 \\
\hline Ugly-beautiful & 41.75 & 19.37 & 56.92 & 7.20 & 66.69 & 13.57 & 59.73 & 8.16 \\
\hline Fat-thin & 41.08 & 15.32 & 52.13 & 6.08 & 56.46 & 19.38 & 52.15 & 9.98 \\
\hline Grade & 5.88 & 1.21 & 6.66 & 0.47 & 7.08 & 0.79 & 6.72 & 0.69 \\
\hline
\end{tabular}

Note: For all scales, a higher score represents a more positive rating.

a $\mathrm{HS}=$ high symptomatics.

b $\mathrm{LS}=$ low symptomatics. 
1989). In the current study, high symptomatics also rated similar others (other high symptomatics) as thinner than they are. Finally, it cannot be concluded that high symptomatics have an ultimate lack of the self-serving body image bias when it comes to the judgements made of other women's appearance. Instead, the lack of the self-serving body image bias appears to be specific for weight.

Also unique to the current study is that we were able to demonstrate that low symptomatics rate their own bodies as more attractive and more beautiful than they rate the bodies of other women and of other low symptomatics specifically. This finding supports previous research that has shown that healthy women make less self-defeating social comparisons than eating disordered women do (Corning et al., 2006). It also evidences the presence of the self-serving body image bias in healthy individuals that has been reported in a previous study on the same sample but which used different judges to compare the self-judgments with (Jansen et al., 2005). Importantly, the novel contribution of the current study is that participants rated their own bodies, in addition to the bodies of all other participants, which provides stronger support of the self-serving body image bias. Again, it seems that the tendency to see with 'rose-coloured glasses' may be vital to mental health and well-being, also when body image is considered. It is important to note that low symptomatics did not rate other bodies as thinner than their own, although they judged their own bodies more attractive and beautiful. For low symptomatics, it could be that attractiveness and beauty are not synonymous with thinness. Moreover, for them, attractiveness and beauty may be the more self-relevant dimensions from which they derive their self-worth.

With regard to the participants' expectations regarding the judgment of the 'average Dutch male,' high symptomatics expected males to rate other bodies more positively than their own bodies (on all aspects measured). In contrast, low symptomatics expected males to rate other bodies no differently than their bodies. If low symptomatics indeed have a self-serving body image bias, one would expect them to think that men would find them more attractive, beautiful and thin than others. One explanation is that low symptomatics find themselves more attractive than they think that others do. However, it is also possible that low symptomatics expect men to have different standards in terms of what constitutes attractiveness (e.g., beauty may be less important than sexiness). Therefore, for future research, it would be insightful to include other aspects of appearance (e.g., sexiness) that women can rate from the male perspective.

An important note concerning the methodology of the current study is that participants were aware of which body photograph was their own. This was done to ensure that there were no differences between participants in recognition of their own bodies (which may have otherwise influenced the results). In future experiments, it may be interesting to investigate the attractiveness ratings when participants are unaware of which body is their own, and which body belongs to another participant.

These findings have important clinical implications. In practice, mirror exposure is often conducted in group format. However, the mechanisms and effects of this treatment have not been completely unravelled yet. Considering the finding that high symptomatics judged other high symptomatics as thinner than they are, it is necessary to consider this potential impediment to group mirror exposure. Given that thinness is a self-relevant and valued dimension for high symptomatics, they may feel more negatively if they perceive their own bodies are fatter than the bodies of their fellow peers. This self-defeating social comparison may lead to greater distress or reduced feelings of self-worth, which would impede the therapeutic process. It may therefore be beneficial to conduct mirror exposure individually, at least initially, in order to prevent the negative impact of self-defeating comparisons before therapy progresses.
Finally, as a self-serving body image bias appears to be a feature of women with low levels of eating disorder symptoms, the therapist may wish to train this positive bias in the patient. To date, guided mirror exposure programs have been tested that employ positive guidance (instead of neutral guidance, or pure exposure; Luethcke et al., 2011; Stice \& Presnell, 2007). These programs have often been termed "cognitive dissonance based." In theory, the creation of positive comments about the body may create psychological discomfort (i.e., cognitive dissonance) in women whose second nature is to despise their bodies. In order to reduce this dissonance, the patient may be taught to adopt a more positive view of the body, consequently reducing body dissatisfaction. Drawing from the current findings, it is possible that the repeated use of this variant of mirror exposure may also work by eventually leading to the development of a self-serving body image bias in patients, as they become more positive about their bodies. Future studies may investigate whether symptom improvement goes hand in hand with the development of this bias.

One limitation of the present study is the low sample size. Recruiting participants who are high in eating disorder symptomatology, but willing to be photographed in minimal underclothing, proved problematic. This led to a second limitation of the current study, namely that a selection bias may have occurred. Only high symptomatics who were comfortable enough to be photographed in underclothing participated. So, it could be that high symptomatics who are not willing to be photographed may have had higher levels of eating disorder symptomatology. This group of women may or may not show differences when it comes to the way in which they view their own bodies compared to other women's bodies. Finally, another limitation of the current study concerns the lack of a clinical diagnostic interview. Although the EDE-Q measures eating disorder symptomatology, conducting a structured clinical interview would have provided specific diagnostic information (e.g., how many participants classified as anorexic or bulimic). For future research, it may be important to examine whether or not diagnostic status influences the results of similar studies.

The current study added to the extant literature by demonstrating that high symptomatics see other women's bodies and the bodies of other high symptomatics as thinner than their own bodies. Further, the presence of the self-serving body image bias in low symptomatic women was confirmed. These findings have important clinical implications. Namely, in order to help high symptomatic individuals optimally, it may be necessary to conduct mirror exposure individually. As a result, it may be possible to improve the way that high symptomatics 'see' their own and each other's bodies. At a more general level, the current study also demonstrated that eating disordered individuals make self-defeating comparisons with other women on a particularly self-relevant, salient dimension; namely, thinness. It will be vital for future research to investigate methods that may alter the social comparison processes of eating disordered individuals.

\section{References}

Brewin, C. R. (1993). Cognitive foundations of clinical psychology. Hove: Erlbaum.

Corning, A. F., Krumm, A. J., \& Smitham, L. A. (2006). Differential social comparison processes in women with and without eating disorder symptoms. Journal of Counseling Psychology, 53, 338-349.

Delinsky, S. S., \& Wilson, G. T. (2006). Mirror exposure for the treatment of body image disturbance. International Journal of Eating Disorders, 39, 108-116.

Fairburn, C. G. (2008). Cognitive behaviour therapy and eating disorders. New York, NY: The Guilford Press.

Fairburn, C. G., \& Beglin, S. J. (1994). The assessment of eating disorders. Interview or self-report questionnaire? International Journal of Eating Disorders, 16, 363-370.

Festinger, L. (1954). A theory of social comparison processes. Human Relations, 7, 117-140. 
Hay, P., \& Fairburn, C. G. (1998). The validity of the DSM-IV scheme for classifying bulimic eating disorders. International Journal of Eating Disorders, 23, 7-15.

Hilbert, A., Tuschen-Caffier, B., \& Vögele, C. (2002). Effects of prolonged and repeated body image exposure in binge-eating disorder. Journal of Psychosomatic Research, 52, 137-144.

Jansen, A., Bollen, D., Tuschen-Caffier, B., Roefs, A., Tanghe, A., \& Braet, C. (2008). Mirror exposure reduces body dissatisfaction and anxiety in obese adolescents. A pilot study. Appetite, 51, 214-217.

Jansen, A., Nederkoorn, C., \& Mulkens, S. (2005). Selective visual attention for ugly and beautiful body parts in eating disorders. Behaviour Research and Therapy, 43, 183-196.

Jansen, A. Smeets, T., Martijn, C. \& Nederkoorn, C. (2006). I see what you see. The lack of a self-serving body-image bias in eating disorders. British Journal of Clinical Psychology, 45, 123-135.

Luce, K. H., \& Cwother, J. H. (1999). The reliability of the Eating Disorder Examination self report questionnaire version (EDE-Q). International Journal of Eating Disorders, 25, 349-351.

Luethcke, C. A., McDaniel, L., \& Becker, C. B. (2011). A comparison of mindfulness, nonjudgmental, and cognitive dissonance-based approaches to mirror exposure. Body Image, 8, 251-258.
Moreno-Dominguez, S., Rodriguez-Ruiz, S., Fernandez-Santaella, M. C., Jansen, A., \& Tuschen-Caffier, B. (2012). Pure versus guided mirror exposure to reduce body dissatisfaction. A preliminary study with university women. Body Image, 9 285-288.

Morrison, T. G., Kalin, R., \& Morrison, M. A. (2004). Body image evaluation and body image investment among adolescents. A test of sociocultural and social comparison theories. Adolescence, 39, 571-592.

Myers, T. A., \& Crowther, J. H. (2009). Social comparisons as a predictor of body dissatisfaction. A meta-analytic review. Journal of Abnormal Psychology, 118, 683-698.

Smeets, E., Jansen, A., \& Roefs, A. (2011). Bias for the (un)attractive self. On the role of attention in causing body (dis)satisfaction. Health Psychology, 3, 360-367.

Stice, E. (2002). Risk and maintenance factors for eating pathology. A meta-analytic review. Psychological Bulletin, 128, 825-848.

Stice, E., \& Presnell, K. (2007). The body project. Promoting body acceptance and preventing eating disorders. New York, NY: Oxford University Press.

Wilfey, D. E., Schwartz, M. B., Spurrell, E. B., \& Fairburn, C. G. (1997). Assessing specific psychopathology of binge eating disorder patients. Interview or self report? Behaviour Research and Therapy, 35, 1151-1159.

Wood, J. V. (1989). Theory and research concerning social comparisons of personal attributes. Psychological Bulletin, 106, 231-248. 